DOI: $10.2478 / \mathrm{v} 10235-011-0008-\mathrm{z}$

\author{
Rodrigo de Sá-Saraiva \\ Ana Isabel de Sá-Saraiva
}

\title{
On the Acheulean origin of mind and language
}

\section{Introduction}

Neither of the authors are archaeologists; therefore our aim is not to delve into archaeological minutiae, but to understand how cognitive evolution as represented in archaeological finds may inform us about the evolution of language. The need for a more precise conceptual correspondence between cognition and archaeological data has been argued by Botha (2010) and this paper may be interpreted as an effort in answering the question: what do some of the "modern" (that is, sapiens-like) behaviour indexes mean in terms of cognition? This is, therefore, a conceptual analysis, and the factual proposal that it contains about the origin of language may be modified by new data. Our main contribution aims to be about the psychological meaning of some data patterns found in archaeology. This kind of theoretical exercise must rely on fairly high-level concepts, such as "Acheulean," "biface," "memory," "theory of mind" or "intentional agents." This is because archaeological and psychological concepts developed independently and no precise equivalence in details is possible. To give an example, it is possible to approach Palaeolithic industries as chaînes opératoires (Boeda 1994), typologies (Bordes 1961/2000), or even visual classification (Sinclair \& McNabb 2005); likewise, the cognitive psychology theoretical approach is arguably too fragmented and too interested in micro theories to be useful as a guide to the interpretation of archaeological data. We will, therefore, use fairly broad concepts (as did Coolidge \& Wynn 2009) to try to link ethology, psychology and archaeology. Should a more systematic approach be conducted, there is room for a new theoretical body of archaeopsychological concepts to evolve. 
Language does not translate into archaeology but the behavioural results of language do. The archaeology of language is difficult to tell apart from the behavioural results of symbolic reference and episodic memory. In consequence, the archaeological search for the history of language is no different from the search for the history of the modern mind.

In this paper we will try to reconstruct the cognitive modifications that led to language. Let us begin with a statement of what we consider to be the cognitive hallmarks of a modern mind and how they translate into the archaeological record.

\section{Language, relations, mental images, and connotation}

Modern language depends on many psychological aspects - grammar, symbolic reference, memory, attention (and, of course, of many non psychological aspects as well). Several different hypotheses of mental evolution allowing the appearance of language have been put forward, accounting for different aspects of language (for instance, Deacon 1997, focused on symbolic reference, whereas Coolidge \& Wynn 2005, 2009, concentrated on working memory sensu Baddeley 2007). However, to our knowledge, no one has proposed that symbolic reference or memory, do not, by themselves, account for language: if an organism has a way to refer one representation to another representation, it is necessary to specify what kind of relationships are possible between the two signifiers. Thus, for reference to be possible, there must be both a memory "space" in which to perform that reference, and rules that specify what kind of relationships may be represented.

In non-human vertebrates, there seem to be at least two kinds of connections between a stored memory and a referent (Sá-Nogueira-Saraiva 2003): either motivational belongingness (Seligman 1970, Shettleworth 1975,2010 ) or true stimulus-stimulus association (e.g. Rescorla \& Wagner 1972, see also Pearce 1997, 2002 and Haselgrove et al. 2005). In the first case, a neutral stimulus is reclassified as a learned releaser for a given motivational centre (sensu Baerends 1970, 1976, Tinbergen 1951, 1969 and Hinde 1982). In the second case, the memory trace of a stimulus or a response is connected to the memory trace of a specific event (usually, but not necessarily, a reinforcer; see Pearce 1997, and review in Sá-Nogueira Saraiva 2003). The connections seem to broadly follow Hume's association laws: when noticing a given stimulus the animal "knows," in the "memory space," what is going to happen next. 
If symbolic reference is to go beyond mere association (as it certainly does), it is necessary to describe the rules governing what may be represented as the relation between two representations: is the relation temporal (A before $B$ ), spatial (A next to $B$ ), same-different ( $A=B$ ), motivational ( $A$ is a predator), part-whole (A is part of $\mathrm{B}$ ), class belonging ( $\mathrm{A}$ and $\mathrm{B}$ belong to the same class) or perceptive (A has the same shape as B)? If mere association were to provide all the connections, we would be unable to say more about the relationship between two different events, $A$ and $B$, than just « $\mathrm{A}$ and $\mathrm{B}$ », that is, the memory or perception of $\mathrm{A}$ (or $\mathrm{B}$ ) would recall the memory of B (or A). Instead, we may say much more. For instance, we may say that $A$ is on top of $B$, that $A$ is besides $B$, that the behaviour of $A$ is parallel to the behaviour of $\mathrm{B}$, that $\mathrm{A}$ is connected to $\mathrm{B}$, that $\mathrm{A}$ caused $\mathrm{B}$, that $A$ happened before $B$, that $A$ is the inverse of $B$, and many other relations. One of us (Sá-Nogueira Saraiva 2003) tried to unravel some of those rules and termed them praxianaphoric grammar (from the Greek, práxis, action, and anaphorá, relation of one thing to another); the concept of praxianaphorics describes the relations between objects and substances. Here we will propose the concept of psycheanaphorics, from the Greek psyche, soul, to refer to the tendency we have to understand animated objects as minded agents (the concepts of what is usually termed "theory of mind," originally proposed by Premack \& Woodruff 1978, and of "intentional agents" and "intentional stance" by Dennett 1996, are relevant in this context). Thus A likes B, A intends x, A knows y; A has emotion/motivation z. Praxi- and psycheanaphoric rules structure what is perceived and what is recalled and imagined in memory (for two different but convergent theoretical positions see Boyer 2001, Pinker 2007, and Penn et al. 2008). ${ }^{1}$ We will call these two sets of rules "Anaphorics."

Anaphorics require several things to be linked into a coherent whole, as Gestalt theorists claimed long ago (e.g. Köhler 1929/2000) and this Gestalt tendency, itself, requires working memory to be sufficiently large to chunk several episodes together ("episodic memory", Tulving 2002).

For episodic memory to exist, it is necessary that a subject be able to perceive a field of events within memory: when I recall that a tree almost fell upon me, I am the epistemic subject (I) and all the recollections (me, the tree, its felling) are objects of my attention (and are, in turn, organised

1 Penn et al. state their relational reinterpretation hypothesis thus: “...the discontinuity between human and nonhuman minds extends... to any cognitive capacity that requires reinterpreting perceptual relations in terms of higher-order, structural, role-governed relations" (Penn at al. 2008: 127). 
as subjects and objects and several other linguistic classes - see Pinker 1994: 106-120, for a clear discussion). The I (the nominative form, or perpendicular pronoun, that is, "I, Eu, Yo, Je, Ich, Io, Ja," not the self, "me") is the word we use to refer to this phenomenal point which can "see" in memory (the difference between the I and the me was made previously by W. James 1890/1981 and G. H. Mead 1934; V. Ferreira 1969, independently presented a phenomenic approach to the subject; Sá-Nogueira Saraiva 2003, reached the distinction from an ethological analysis of human behaviour; finally A. Damásio 1999, and chiefly 2010, again stressed the difference between subject and object).

The efficacy of the mind greatly increases if the complexity of things to be related to each other is reduced. In our species this happens through reduction of things to prototypes (Rosch 1978, 1981, Rosch et al. 1976, Lakoff 1987) that are perceptually well formed ("good shape"), that is, closed in the sense of Gestalt theorists. This tendency appears early in humans (children of about 2-3 years reject imperfect toys, as first noticed by Kagan 1981). Because of prototype reduction and Gestalt reduction, the representations of things in our minds are simplified and fit into memory (Collins \& Quillian 1969). This simplification seems to be mandatory in our species, so that every object and agent must be reduced to a class (kind of object, class of agent; e.g.: furniture versus cutlery, friend versus foe). Prototypes are given names and therefore allow language, verbal thinking and communication. Summing up, prototypes systematically duplicate things in the mind by giving them a name, this name works as a handle for the meaning under the prototype, and these handles can be related through anaphorics. This might be considered the core of symbolic representation (Sá-Nogueira Saraiva 2003).

When clear representations are possible in the mind, it becomes possible both to recognise similarities between those images and perceptions (as we often do when we take time to look at clouds and the forms they conjure up) and to project these forms into matter (when we draw or make a statue).

Another important aspect is connotation. In other species connotation depends on the biological properties of releasers and on associations based on the pairing of releasers and neutral stimuli; that is, if releaser A is associated with neutral stimulus B, B acquires the motivational properties of releaser A. In our species this changes greatly because we may attribute importance and power to almost anything (as in "mana," Coddrington 1891). This feature has probably to do with power and agency (as was found by Osgood 1952). To show the importance - the mana- of a thing and to communicate about it, we have to draw attention to it, and this is done through ritual and through particular treatment of that thing (for instance, in medieval times, relics were 
protected inside precious casings; in our time, a national flag is treated with respect and is often put in a prominent place). The thing to which one wants to draw attention is, therefore, marked. This marking behaviour is important in archaeology, as we will see.

How do modern mind and language translate into archaeology? If we take the Upper Palaeolithic in Europe as an example, we will find that all the features presented above are reflected on the vestiges. Thus, form imposition is very clear (see Klein 1999, 2000, for the argument that form imposition is far greater in the Upper Palaeolithic than before), as we would expect from prototype reduction; also, we find images and sculpture (Clottes 2001, White 2003, Conard \& Bolus 2003), which is congruent with the idea that the mind imposes its images to matter. Anaphorics are very clear, in two senses: most manufactured items are made from more than one part thus forming a new whole (blades and shafts, multipart tools and complex dwelling structures); Reynolds (1993) called these structures polyliths. The other anaphoric trait is marking, which appears in decoration and pigment use. Putting ochre on something may just be a consequence of a Piagetian circular reaction - the intrinsically reinforcing effect of relating two objects; however, marking with a specific colour (red ochre) implies that the ochre is put on something that the marker wants others to appreciate. If the marker anticipates the reactions to his/her marking, (s)he is displaying theory of mind in the sense of Premack and Woodruff: (s)he knows that another agent will interpret the mark. The marker expects others to attend to the marked object or body and to attribute a meaning to it; as only minds can attribute meaning, we submit that ochre is evidence of theory of mind. As is widely known (e.g. Klein 1999) ochre was abundantly used in the Upper Palaeolithic. Even if the application of ochre may be explained just by reinforcement - putting ochre on one's body might have an effect on other people's behaviour - it seems to us that it would only be reinforcing if the other person would recognize the ochre marking as a meaning of some hidden properties of the bearer of the ochre. As hidden properties of agents are usually interpreted according to the intentional stance, even if ochre was used as a consequence of other people's reaction to it, ochre use still suggests the presence of a sapiens-like theory of mind.

\section{Mind evolution}

In spite of being the result of autonomously evolved lineages (Gibbons 2009), the great apes have been studied with a view to establishing a kind 
of baseline ability from whence hominins evolved (Savage-Rumbaugh 1986, Savage-Rumbaugh \& Lewin 1994, Toth et al. 1993, Gowlett 2009, Whiten et al. 2009).

The available data are controversial in the sense that different approaches seem to yield different kinds of result (as witnessed by the contrasting interpretations of de Waal 1998, Savage-Rumbaugh 1986, Savage-Rumbaugh \& Lewin 1994, Boesch \& Boesch-Achermann 2000, on one side, and Tomasello \& Call 1997, Povinelli 2000, Penn et al. 2008, on the other). A conservative yet rigorous approach suggests that in spite of their considerable behavioural plasticity, apes (chimpanzees being the most studied species) differ a great deal from humans in cognitive terms. Thus, they do not naturally form polilyths, they seem to lack a complex grammar of connections between things (Penn et al. 2008) even if they do use tools sequentially as has been repeatedly observed (e.g. Carvalho et al. 2008, Sanz \& Morgan 2009); they are also unable to attribute complex psychological states to other agents (Povinelli 2000, Penn et al. 2008, Call \& Tomasello 2008, Kaminski et al. 2008), and to communicate about absent entities (Liszkowski et al.2009). Therefore, they lack a theory of mind in the original sense of the term even if they cannot be characterized as totally lacking that capacity, as they are able to understand conspecifics as behavioural entities that possess knowledge (Call \& Tomasello 2008, Kaminski et al. 2008). Also, apes seem to be less interested in relations between things (secondary circular reactions) than human infants (Vauclair \& Bard 1983). They also seem to keep record of reciprocity between members of groups (Tomasello and Call 1997) and perhaps possess some foresight (Osvath \& Osvath 2008, pace Suddendorf et al. 2009), a limited amount of metacognition (Call 2010) and a kind of precursor of our species' episodic memory (MartinOrdas et al. 2010).

Even if the social intelligence of chimpanzees is probably not achieved through psychological state attribution as in our species, the primate data corpus does show that animals other than humans rely on more than just associative learning and biological constraints on stimulus and reinforcement "belongingness". Therefore, there is a kind of anaphoric logic, but probably not a truly psycheanaphoric one.

In sum, chimpanzees seem limited either in terms of praxianaphoric and psycheanaphoric rules, when compared to modern humans. It is, therefore, important to try to find out the sequence of these developments in the evolution of Homo.

Our data on hominin behaviour consists predominantly of lithic materials. Other very old remains are seldom available (stone marks on bones, e.g. 
Domínguez-Rodrigo et al. 2009; use of bones as tools, d'Errico \& Blackwell 2003), and in the more recent past, a few bone tools. Because of the dearth of materials interpretation will probably always tend to a conservative estimation of the early Homo cognitive capacities. But it seems to us that there is no need to take such a conservative stand as, for instance, Dibble (1988), Noble \& Davidson (1996) or Coolidge \& Wynn (2009). Given the fact that very few materials other than stone are likely to fossilize (organic material usually doesn't) being too conservative is tantamount to being very certain that we do not accept a false hypothesis, but not bothering about the consequence: that we are equally likely to reject a true one (cf. the statistical notion of type I and II errors of Neyman \& Pearson 1933/1967).

We will treat the Late Acheulean as a different phase in human evolution. The recent validation of Homo heidelbergensis as an Afro-European species makes this decision plausible (Mounier et al., 2009).

With these caveats in mind let us proceed to a very brief review of some data.

Oldowan technology is not complex if compared with more recent ones, but it seems to show an increased interest in relations between things: hominins had to learn the properties of different kinds of rocks; as Australopithecus africanus shows an enhancement of the brain areas related to planning (Falk et al. 2000), we may suppose better anaphorics than in living non human primates. Early Acheulean brings more novelty. If the bifaces were indeed intended as opposed to being the leftovers of an exploited core (Coolidge \& Wynn 2009, Gowlett 2009), the presence of form, however crude, is a testimony of the appearance of a "memory field" in which things are represented. This "memory field" encompasses Baddeley's visuospatial sketch-pad, prospective (Ellis \& Freeman 2008), implicit (Schacter 1987) and motor working memory (which has not received great attention from cognitive psychologists).

It is by the Late Acheulean, however, that we find reason to postulate a proto-language.

\section{Late Acheulean innovations and their meaning}

Form imposition. The evidence for form imposition comes from bifaces which seem to have sometimes been well formed into tri-radial patterns (e.g. Wynn 2000, Le Tensorer 2006). The very scant vestiges of woodworking (Thieme 1997, 2005) corroborate this interpretation, as do the data that suggest that shelters were built in Bilzingsleben (Mania \& Mania 2005) 
and possibly in Terra Amata (Villa 1983): both woodworking and the construction of a shelter were probably done according to a mental plan. The use of prepared cores (short review in Coolidge \& Wynn 2009, 155161 , more in depth analysis in Shipton 2010) further supports this claim. However, most bifaces were still crudely made (e.g. Sinclair \& Mcnabb 2005, could detect no evidence of patterning at the Late Acheulean site of Makapansgat), and in the same site rough bifaces are predominant over well formed ones (Wynn 2000). Indeed, it is interesting to analyze careful drawings of a great deal of material (as in Bordes 1992/2002): in Later Acheulean sites, in spite of clearly well shaped instruments, there are many less well formed ones, and sometimes we were able to detect no form at all. This means that prototypization was possible but it was neither mandatory nor frequent. This hypothesis is strengthened by data from Qesem (Stiner et al. in press): besides many "modern" behavioural traits, the authors find a lack of standardization in meat cutting from bones, which agrees with the lack of mandatory patterning suggested by the non mandatory prototypecapacity suggested above.

It is important to note that "good" form imposition predates the Late Acheulean in some sites (e.g. at Gombore II, in Melka Kunture, about 800ky ago, where carefully shaped bifaces are associated with remains from Homo erectus sensu lato; see Gallotti et al. 2010).

Long sequences of behaviour are attested both by well-formed bifaces, perhaps worked with two kinds of hammers (Wynn 2000), but also by the work on spears, which requires the choice of a tree, removal of the bark, smoothing and point shaping. The find that Late Acheuleans sometimes thickened the soil in order to provide a firmer support for poles (Goren-Inbar et al. 2002) has the same meaning. We do not know very much about the complexity of the structures, but their existence (suspected in several cases, see review in Gamble 1999), together with the manufacture of well shaped bifaces and spears, suggests that there was a well developed praxianaphoric intelligence, linking several operations into an overall plan - episodic memory, therefore, clearly existed. The use of fire (Gamble 1999) has the same meaning. Long sequences of behaviour further imply referential representations, a sense of time (transformation from a previous condition to a new one), conditional decisions, and also a clear differentiation between the I and whatever is not I (as Piaget1937/1998, would have it, the construction of the outside world as different from the agent). Therefore, long sequences imply a hierarchy of goals and sub-goals with conditional decisions; a sense of past, transformation and future through the action of the I. Although learned sequences of behaviour exist in Pan, as we have mentioned, and apes 
have a certain amount of planning capacity, the level of complexity required by Acheulean industries is much greater than the one found in, for instance, chimpanzees (Shipton 2010).

Non-utilitarian practices appear to have been rare, but they seem to have been present. Pigments were used (Groenen 1991, Piperno 2001, Barham 2002, Cruz-Uribe et al. 2003, de Lumley 2007) and the fact that often a particular hue of red (primary red) was selected instead of equivalent but different coloured materials suggests that red had a meaning. This meaning was probably just salience - red is the first colour that our species learns to name, (Berlin \& Kay 1969) - but even in that case the suggestion is clear: salience was being selected to mark things deemed important (either bodies or valued things). As we have seen, marking seems to imply theory of mind, because it is an act of communication of a mental value. The hunting of big game (Thieme 1997, 2005) probably benefited from the attribution of intentions both to fellow hunters and to prey (as "putting myself in the prey's mind" may help in predicting the prey's behaviour during a hunt).

Marking should be linked with the few instances of "odd object collecting" (d'Errico et al. 1989, d'Errico \& Nowell 2000). This is because if odd but non-functional objects were collected, they were attributed a value in the mind, exactly as in marking. Furthermore, odd object collecting may imply reference: crystals were perhaps recognized to have a symmetrical form - a pure Gestalt quality - and the Berekhat Ram figurine may have been recognized as similar to a human body. In both cases, a template was related to an object and that relation was valued. As is well known (see Hodgson 2009, for a review), recognition itself is reinforcing, and in humans symmetry recognition seems to be innate.

\section{Language}

It is, we think, highly probable that a form of language existed by the Late Acheulean. This is suggested by the simultaneous presence of the following features:

a) Mental space in which things and relations between things are represented in a general modality-independent working memory (actions and objects or agents may be relationally represented).

b) Theory of mind: agents are characterized by psychological states (what those states were we do not know). 
c) The I+action: given A, if I perform the action 1 on A, I will get A1; this procedure may be reiterated: given A1, if I perform the action 2 on A1 I will get A1,2. This is the basis of:

d) Long sequences of behaviour with a main goal and subgoals that are represented in memory.

If we assume that all these four conclusions about mental operations are applied to language (and that is, admittedly, a risky assumption) we might be tempted to translate them into a basic grammar (in mentalese; the actual language is unknowable). In fact, the features listed might allow for phrase construction: A "head" (the main goal), objects ( $\approx$ nouns) and actions ( $\approx$ verbs); objects and actions are not necessarily nouns and verbs, but they often are, and we use this correspondence to speculate that Acheuleans had the potential capacity to build the equivalent to both Noun phrases and Verb phrases and to combine them into sentences, although, almost certainly, in a non specifiably different way from our own grammar. As there probably was theory of mind, Acheuleans knew that others were interpreters of their own intentions, and therefore all the conditions for speech were present.

However, we are not claiming Acheulean language to be similar to that of Homo sapiens. As we suggested before, modern language heavily depends on mandatory prototype-reduction, whereas the archaeological data do not suggest that feature to be present in the Acheulean. Even if there definitely is evidence that suggests that prototypization was present (the handaxes, the throwing sticks, and even the possibility of constructions), it was not nearly as systematic as in typical Homo sapiens cultures. The instances of strictly utilitarian forms in Homo sapiens are not frequent (Moran 2000, also Lévi-Strauss 1962), let alone predominant. Even if, as we have seen, there are cases where very clearly imposed forms are present, even before the Late Acheulean (as in Melka Kunture), the relevant point is that not all Acheulean cultures show a majority of strictly form imposed materials, whereas Upper Palaeolithic cultures almost always do. In contrast, most Late Acheulean (and Mousterian) tools look comparatively less form derived, and therefore prototype reduction was not as important as in our species; probably, in the Late Acheulean prototype reduction was possible but not mandatory.

What kind of language can we expect without mandatory prototypes? A language must rely on mental representations because the words (or whatever signifiers are used) refer to these representations. In our species prototypes (sensu Rosch 1981, see also Lakoff 1987) seem to be an important aspect of word meaning representation. But other words are just actions or images. Indeed, in our laboratory we have now amassed a convincing 
body of data suggesting that concepts such as "grasp," "break," "connect" are represented as actions more readily than as in a propositional (in this case linguistic) format and others (like "overflow") are visually represented (Rodrigues 2009). Therefore, even if there are no prototypes, language is still possible, based on more vague visual images and on relations represented as actions.

When there are few prototypes but mainly mental images and actions, language would consist mostly of verbalizations referring to actions performed on physically present agents and objects. Without mandatory prototypes to which each thing that is named must be reduced, virtual action, which is performed on mental icons of things, not on physically present objects, is impossible. Therefore the Acheulean language was probably related to physically present entities, and in spite of the capacity of planning the transformation of a concrete object into a new form it did not allow for the systematic connection and relation of non-visible, non-present entities in the mind. This systematic linguistic duplication of reality into a system of categories that may be manipulated in the memory space is only possible through mandatory prototype reduction.

Acheulean language is therefore probable (there were cognitive capacities to represent verbs and some objects) but it likely did not allow for what Hockett (1960) called "displacement": systematic thinking about nonvisible objects and agents.

No hypothesis on the modality of such a language is made (Corballis 2002, 2009), but the hypoglossal canal may have been in the modern range (Coolidge \& Wynn 2009: 174), therefore the vocal modality is highly probable, perhaps in connection with pointing, as is still the case today in informal communication (McNeil 1992).

\section{Conclusions}

Protolanguage in Late Acheulean is probable.

This protolanguage was likely based on actions, connections and transformations ( $\approx$ verbs).

Protolanguage could communicate about objects and agents that were in the perceptual field of the communicators but not, or at least not easily, on absent agents or objects.

Language as a thinking tool was therefore probably not available (hence conservatism of Lower and Middle Palaeolithic cultures: difficulty of innovation in consequence of "thought experiments"). 
Mandatory prototypes and mental hypothesis probably appeared only with Homo sapiens proper.

Finally, we would like to restate that this paper is an exercise in thinking about what archaeological data mean in terms of cognition. As we said at the beginning, a more complex integration between theory of cognition and archaeological data is needed. This paper is a tentative step in that direction. As new data will be published, it may be that many of the archaeological features we attribute to the Late Acheulean are found to be more ancient. That would mean that the timetable we are proposing would have to be changed, and probably that the conclusions about the kind of language present would have to be modified. But, we hope, it would not harm the links between broad psychological concepts and patterns of archaeological data that we are proposing.

\section{Acknowledgements}

The authors would like to thank Dr. Slawomir Wacewicz and an anonymous reviewer for helpful suggestions and comments.

\section{References}

Baddeley, A. D. (2007). Working Memory, Thought, and Action. Oxford: Oxford University Press.

Baerends, G.P. (1970). A model of the functional organization of incubation behaviour in the herring gull. Behaviour Supplement, 17, 261-312.

Baerends, G.P. (1976). The functional organization of behaviour. Animal Behaviour, 24, 726-738.

Barham, L. (2002). Systematic pigment use in the Middle Pleistocene of SouthCentral Africa. Current Anthropology, 43, 181-90.

Berlin, B. \& Kay, P. (1969). Basic color terms: Their universality and evolution. Berkeley and Los Angeles: University of California Press.

Boeda, E. (1994). Le Concept Levallois: variabilité des methods. Monographie du CRA 9, CNRS editions, Paris

Boesch C. \& Boesch-Achermann, H. (2000). The Chimpanzees of the Tai Forest: Behavioural Ecology and Evolution, Oxford: Oxford University Press

Bordes, F. (1961/2000). Typologie du Paléolithique Ancien et Moyen CNRS Éditions, Paris

Bordes, F. (1992/2002). Leçons sur le Paléolitique, Tome 2, Paléolitique en Europe. Paris, CNRS Éditions 
Botha, R. (2010). On the Soundness of Inferring Modern Language from Symbolic Behaviour. Cambridge Archaeological Journal 20: 3, 345-56

Boyer, P. (2001). Religion Explained: the human instincts that fashion gods, spirits and ancestors. London: William Heinnemann.

Call, J. (2010). Do Apes know that they could be wrong? Animal Cognition, 13: 689-700

Call, J. \& Tomasello, M. (2008). Does the chimpanzee have a theory of mind? 30 years later. Trends in Cognitive Science, 12, 187-192.

Carvalho S., Cunha, E., Sousa, C. \& Matsuzawa, T. (2008). Chaînes opératoires and resource-exploitation strategies in chimpanzee (Pan troglodytes) nut cracking. Journal of Human Evolution, 55, 148-63.

Clottes, J. (ed.) (2001). La Grotte Chauvet: l'Art des Origines. Paris: Seuil.

Codrington, R. H. (1891). The Melanesians: Studies In Their Anthropology And Folklore. Oxford: Clarendon Press.

Collins, A.M. \& Quillian, M. R. (1969). Retrieval time from semantic memory. Journal of Verbal Learning \& Verbal Behavior, 8, 240-248.

Conard, N. J. \& Bolus, M. (2003). Radiocarbon dating the appearance of the modern humans and timing of cultural innovations in Europe: New results and new challenges. Journal of Human Evolution, 44, 331-71.

Coolidge, F. \& Wynn, T. (2005). Working memory, its executive functions, and the emergence of modern thinking. Cambridge Archaeological Journal, 15, 5-26.

Coolidge, F.L. \& Wynn, T. (2009). The rise of Homo sapiens: the evolution of modern thinking. Chichester: Wiley-Blackwell.

Corballis, M. C. (2002). From Hand to Mouth: The Origins of Language. Princeton, NJ: Princeton University Press.

Corballis, M.C. (2009). The gestural origins of language. Wiley Interdisciplinary Reviews: Cognitive Science 1, 2-7.

Cruz-Uribe, K.,Klein, R.G., Avery, G., Avery, M., Halkett, D., Hart, T., Milo, R.G, Sampson, C.G. \& Volman, T.P. (2003). Excavation of buried Late Acheulean (Mid-Quaternary) landsurfaces at Duinefontein 2, Western Cape Province, South Africa Journal of Archaeological Science, 30, 559-575.

d'Errico, F., Gaillard, C., \& Misra V. N. (1989). Collection of non-utilitarian objects by Homo erectus in India. In G. Giacobini (Ed.), Hominidae. Proceeding of the Second International Congress of Human Paleontology (pp. 237-239). Milano: Jaka Book, Milano.

d'Errico, F. \& Nowell, A. (2000). A new look at the Berekhat Ram figurine: Implications for the origins of symbolism. Cambridge Archaeological Journal, 10, 123-67.

d'Errico, F. \& Backwell, L.R. (2003). Possible evidence of bone tool shaping by Swartkrans early hominids Journal of Archaeological Science, 30, 1559-1576.

Damásio, A. (1999). The Feeling of What Happens: Body and Emotion in the Making of Consciousness. San Diego, CA: Harcourt.

Damásio, A. (2010). O livro da consciência: a construção do cérebro consciente. Lisboa: Círculo de Leitores. 
de Lumley, H. (2007). La Grande Histoire des premiers hommes européens. Paris: Odile Jacob.

de Waal, F. (1998). Chimpanzee politics: power and sex among apes, Revised Edition. Baltimore and London: Johns Hopkins University Press.

Deacon, T. (1997). The symbolic species: the co-evolution of language and the human brain. New York: Norton \& Co.

Dennett, D.C. (1996). Kinds of Minds : Toward an Understanding of Consciousness. New York: Basic Books.

Dibble, H.L. (1988). The interpretation of Middle Palaeolithic scraper reduction patterns. Études et Recherches Archéologiques de l'Université de Liège, 31, $49-58$.

Domínguez-Rodrigo, M., Mabulla, A., Bunn, H.T., Barba, R., Diex-Martin, F, Egeland, C.P., Espílez, E., Egeland, A., Yravedra, J. \& Sánchez, P. (2009). Unraveling hominid behavior at another anthropogenic site from Olduvai Gorge (Tanzania): new archaeological and taphonomic research at BK, Upper Bed II. Journal of Human Evolution, 57, 260-283.

Ellis, J.A. \& Freeman, J.E. (2008). Ten years on: realising delayed intentions. In M. Jliegel, M. A. McDaniel, \& G. O. Einstein (Eds) Prospective memory: Cognitive neuroscience, developmental and applied perspectives (1-27). New York: Lowrence Erlbaum.

Falk, D., Redmond Jr., J.C., Guyer, J., Conroy, G.C., Recheis, W., Weber, G. W. \& Seidler, H. (2000). Early hominid brain evolution: a new look at old endocasts. Journal of Human Evolution, 38, 695-717.

Ferreira, V. (1969). Invocação ao meu corpo. Lisboa: Bertrand.

Gallotti, R., Collina, C., Raynal, J-P., Kieffer, G., Geraads, D. \& Piperno, M. (2010). The Early Middle Pleistocene Site of Gombore II (Melka Kunture, Upper Awash, Ethiopia) and the issue of Acheulian bifacial shaping strategies. African Archaeology Review, 27: 291-322.

Gamble, C. (1999). The Palaeolithic Societies of Europe, Cambridge: Cambridge University Press.

Gibbons, A. (2009). A New Kind of Ancestor: Ardipithecus Unveiled. Science 2 October 2009: 36-40.

Goren-Inbar, N., Werker, E. \& Feibel, C. S. (2002). The Acheulian Site of Gesher Benot Ya'aqov, Israel: The Wood Assemblage. Oxford: Oxbow Books.

Gowlett, J. A. J. (2009). Artefacts of apes, humans and others: towards a comparative assessment and analysis. Journal of Human Evolution, 57, 401-410.

Groenen, M. (1991). Présence de matières colorants dans l'Europe paléolithique. Anthropologie et Préhistoire 102: 9-28.

Haselgrove, M., George, D. N., \& Pearce, J. M. (2005). The discrimination of structure: III. Representation of spatial relationships. Journal of Experimental Psychology: Animal Behavior Processes, 31, 433-448.

Hinde, R. A. (1982). Ethology; its nature and relations with other sciences. Oxford and Glasgow: Oxford University Press and Fontana Paperbacks.

Hockett, C. F. (1960). The origin of speech. Scientific American, 203, 88-96. 
Hodgson, D. (2009). Evolution of the visual cortex and the emergence of symmetry in the Aucheulan techno-complex. Comptes Rendus Palevol, 8, 93-97.

James, W. (1890/1981). The Principles of Psychology, Cambridge, MA: Harvard University Press.

Kagan, J. (1981). The second year: the emergence of self-awareness. Cambridge, MA.: Harvard University Press.

Kaminski, J, Call, J., \& Tomasello, M. (2008). Chimpanzees know what others know, but not what they believe. Cognition, 109, 224-234.

Klein, R. G. (1999). The Human Career: human biological and cultural origins, $2^{\text {nd }}$ Ed. Chicago and London: The University of Chicago Press.

Klein, R.G. (2000). Archaeology and the Evolution of Human Behavior. Evolutionary Anthropology, 9, 17-36.

Köhler, W. (1929/2000). La Psychologie de la Forme. Paris: Gallimard.

Lakoff, G. (1987). Women, fire and dangerous things, Chicago: University of Chicago Press.

Le Tensorer, J.-M. (2006). Les cultures acheuléennes et la question de l'émergence de la pensée symbolique chez Homo erectus à partir des données relatives à la forme symétrique et harmonique des bifaces. Comptes Rendus Palevol 5 , $127-135$.

Lévi-Strauss, C. (1962). La Pensée Sauvage. Paris: Plon.

Liszkowski, U., Schäfer, M., Carpenter, M. \& Tomasello, M. (2009). Prelinguistic infants, but not chimpanzees, communicate about absent entities. Psychological Science, 20, 654-660.

Mania, D. \& Mania, U. (2005). The natural and socio-cultural environment of Homo erectus at Bilzingsleben, Germany. In C. Gamble and M. Porr (Eds.) The Hominid Individual in Context. Archaeological Investigations of Lower and Middle Palaeolitic Landscapes, Locales, and Artefacts (pp. 98-114). London: Routledge.

Martin-Ordas, G., Haun, D., Colmenares, F. \& Call, J (2010). Keeping track of time: evidence for episodic-like memory in great apes. Animal Cognition, 13: 331340.

McNeil, D. (1992). Hand and Mind: what gestures reveal about thought. Chicago: University of Chicago Press.

Mead, G. H. (1934). Mind, Self, and Society: From the Standpoint of a Social Behaviorist. Chicago: University of Chicago Press.

Moran, E. (2000). Human Adaptability: an Introduction to Ecological Anthropology, 2nd edition, Boulder and Oxford: Westview Press.

Mounier, A., Marchal, F. \& Condeni, S. (2009). Is Homo heidelbergensis a distinct species? New insight on the Mauer mandible. Journal of Human Evolution, 56, 219-246.

Neyman, J. \& Pearson, E. S. (1933/1967). The testing of statistical hypotheses in relation to probabilities a priori. Joint Statistical Papers. Cambridge, Cambridge University Press, 186-202. 
Noble, W. \& Davidson, I. (1996). Human Evolution, Language and Mind: a psychological and archaeological inquiry. Cambridge: Cambridge University Press.

Osgood, C. E. (1952). The nature and measurement of meaning. Psychological Bulletin, 49, 197-237.

Osvath, M. \& Osvath, H. (2008). Chimpanzee (Pan troglodytes) and orangutan (Pongo abelii) forethought: self-control and pre-experience in the face of future tool-use. Animal Cognition, 11: 661-674.

Pearce, J. M. (1997). Introduction to Animal Learning and Cognition, $2^{\text {nd }}$ ed. Hove and London: Erlbaum.

Pearce, J. M. (2002). Evaluation and development of a connectionist theory of configural learning. Animal Learning and Behavior. 30, 73-95.

Penn, D. C., Holyoak, K..J. \& Povinelli, D. J. (2008). Darwin's mistake: Explaining the discontinuity between human and nonhumas minds. Behavioral and Brain Sciences, 31, 109-178.

Piaget, J. (1937/1998). La construction du reel chez l'enfant. Neuchâtel: Delachaux et Niestlé.

Pinker, S. (1994). The Language Instinct. Harmondsworth: Penguin.

Pinker, S. (2007). The Stuff of Thought: Language as a window into human nature. London: Penguin, Allen Lane.

Piperno, M. (2001), La préhistoire de Melka Kunturé (Éthiopie), Bulletin du Centre de recherche français à Jérusalem, 8 | 2001, retrieved 3-2-2011 from: http:// bcrfj.revues.org/index 1962.html

Povinelli, D. J. (2000). Folk Psychology for Apes: The chimpanzee's theory of how the world works. Oxford and New York: Oxford University Press.

Premack, D. \& Woodruff, G. (1978). Does the chimpanzee have a theory of mind? The Behavioral and Brain Sciences, 4, 515-526.

Rescorla, R. A. \& Wagner, A. R. (1972). A theory of pavlovian conditioning; variations in the effectiveness of reinforcement and nonreinforcement. In A. Black \& R. Prokasy (Eds.), Classical Conditioning II (pp. 64-99). New York: Appleton.

Reynolds, P. C. (1993). The complementation theory of language and tool use. In K. R. Gibson \& T. Ingold (Eds.), Tools, Language and Cognition in Human Evolution (pp. 407-428). Cambridge: Cambridge University Press.

Rodrigues, G. (2009). Análise de discurso, gestos e expressões faciais, pela expressão de conceitos, corrobora a Teoria da Inteligência Praxianafórica. Unpublished thesis.

Rosch, E. (1978). Principles of categorization.In E. Rosch and B. Lloyd (Eds.), Cognition and categorization (pp. 24-48). Hillsdale: Lawrence Erlbaum.

Rosch, E. (1981). Prototype classification and logical classification: the two systems. In E. Scholnick (Ed.), New Trends in Cognitive Representation: challenges to Piaget's theory (pp. 73-86). Hillsdale, N.J.: Lawrence Erlbaum. 
Rosch, E., Simpson, C. \& Miller, R. S. (1976). Structural bases of tipicality effects. Journal of Experimental Psychology: Human perception an performance, 2, 491-502.

Sá-Nogueira Saraiva, R. de (2003). Mundos Animais, Universos Humanos: análise comparada das representações do ambiente. Lisboa: Gulbenkian.

Sanz, C. M. \& Morgan, D. B. (2009). Flexible and persistant toll-using strategies in honey-gathering by wild chimpanzees. International Journal of Primatology, 30, 411-427.

SavageRumbaugh, E. S. (1986). Ape language: from conditioned responses to symbol. New York: Columbia University Press.

Savage-Rumbaugh, E. S. \& Lewin, R. (1994). Kanzi, the ape at the brink of the human mind. New York: John Wiley.

Schacter, D. L. (1987). Implicit memory: history and current status. Journal of Experimental Psychology: Learning, Memory, and Cognition, 13, 501-518.

Seligman, M. E. P. (1970). On the generality of the laws of learning. Psychological Review, 77, 406-418.

Shettleworth, S. J. (1975). Reinforcement and the organization of behavior in golden hamsters; hunger, environment and food reinforcement. Journal of Experimental Psychology, 104, 56-87.

Shettleworth, S.J. (2010). Cognition, Evolution and Behavior, $2^{\text {nd }}$ Edition. Oxford: Oxford University Press.

Shipton, C. (2010) Imitation and shared intentionality in the Acheulean. Cambridge Archaeological Journal, 20, 197-210.

Sinclair, A. \& McNabb, J. (2005). All in a day's work. Middle Pleistocene individuals, materiality and the lifespace at Makapansgat, South Africa. In C. Gamble \& M. Porr (Eds.), The Hominid Individual in Context: Archaeological Investigations of lower and Middle Plaeolithic landscapes, locales and artefacts. Routledge, London and New York.

Stiner, M. C., Gopher, A. \& Barkai, R. (in press). Hearth-side socioeconomics and paleoecology during the late Lower Paleolitich at Qesem Cave, Israel. Journal of Human Evolution.

Suddendorf, T., Corballis, M. C. \& Collier-Baker, E. (2009). How great is great ape foresight? Animal Cognition, 12: 751-754.

Thieme, H. (1997). Lower Palaeolithic hunting spears from Germany. Nature, 385, 807-10.

Thieme, H. (2005). The Lower Palaeolithic art of hunting: The case of Schoningen 13 11-4, Lower Saxony, Germany. In C. Gamble and M. Porr (Eds.) The Hominid Individual in Context. Archaeological Investigations of Lower and Middle Palaeolitic Landscapes, Locales, and Artefacts (pp. 115-32). New York: Routledge.

Tinbergen, N. (1951). The Study of Instinct. New York and Oxford: Oxford University Press, Third printing, 1976.

Tinbergen, N. (1969). Introduction to The Study of Instinct, 1969 reprint. 
Tomasello, M. \& Call, J. (1997). Primate Cognition, New York and Oxford: Oxford University Press.

Toth, N., Schick, K. D., Savage-Rumbaugh, E. S., Sevcik, R. \& Rumbaugh, D. M. (1993). Pan the tool maker: investigations into the stone tool-making and tool-using capabilities of the bonobo (Pan paniscus). Journal of Archaeological Science, 20, 81-91.

Tulving, E. (2002). Episodic memory: From mind to brain. Annual Review of Psychology, 53, 1-25.

Vauclair, J. \& Bard, K. (1983). Development of manipulations with objects in ape and human infants. Journal of Human Evolution, 12, 631-645.

Villa, P. (1983). Terra Amata and the Middle Pleistocene Archaeological Record of Southern France. Berkeley, CA: University of California Press.

White, R. (2003). Prehistoric art: the symbolic journey of humankind. New York: Harry N. Abrams Inc. Publishers.

Whiten, A., Schick, K. \& Toth, N. (2009). The evolution and cultural transmission of percussive technology: integrating evidence from palaeoanthropology and primatology. Journal of Human Evolution, 57, 420-435.

Wynn, T. (2000). Symmetry and the evolution of the modular mind. In P. Carruthers \& A. Chamberlain (Eds.), Evolution and the human mind: modularity, language and meta-cognition (pp. 113139). Cambridge: Cambridge University Press. 